УдК 330.142

DOI 10.18101/2304-4446-2020-3-75-80

\title{
ТРАКТОВКА ПРИБЫЛИ В РАМКАХ БАЛАНСОВЫХ КОНЦЕПЦИЙ УЧЕТА
}

\section{(C) Янданова Цыремжит Николаевна}

кандидат экономических наук, доцент, Бурятский государственный университет имени Доржи Банзарова Россия, 670000, г. Улан-Удэ, ул. Смолина, 24a

E-mail: bzn77@mail.ru

Статья посвящена анализу трактовок прибыли с точки зрения основных балансовых концепций учета. Последовательно рассматриваются особенности и ограничения методологии формирования финансовых результатов в рамках статической концепции, которая легла в основу теоретических конструкций МСФО, а также влияние принципов динамической концепции учета на действующий порядок определения финансовых результатов хозяйствующих субъектов. Рассмотрены основные различия между понятиями «расходы» и «затраты», приведен анализ основных бухгалтерских приемов, регулирующих формирование финансовых результатов с точки зрения реализации принципов идентификации, начислений, соответствия доходов и расходов. Подчеркивается условность и неоднозначность величины прибыли вследствие субъективности в оценке амортизации, начислении резервов, распределении косвенных затрат, способах расчета израсходованных и проданных материалов, товаров и готовой продукции.

Ключевые слова: прибыль; статическая концепция; динамическая концепция; доходы; расходы; международные стандарты финансовой отчетности (МСФО).

\section{Для цитирования}

Янданова Ц. Н. Трактовка прибыли в рамках балансовых концепций учета // Вестник Бурятского государственного университета. Экономика и менеджмент. 2020. № 3. C. $75-80$.

Понимание трактовок прибыли следует рассматривать с точки зрения ключевых факторов развития бухгалтерского учета, определяющих его содержание. Речь идет об основных балансовых концепциях (статической и динамической), оказывающих влияние как на собственно методологию бухгалтерского учета, так и на его предмет. На сегодняшний день нет единого понимания прибыли, поскольку имеется множество целей, стоящих перед заинтересованными пользователями, поэтому важно знать о том, что именно бухгалтерская трактовка прибыли предопределяет ее экономическую величину.

Общеизвестны следующие цели, которые преследуют пользователи при расчете прибыли: 1) оценка эффективности деятельности компании; 2) определение базы для налогообложения; 3) принятие инвестиционных решений в отношении этой компании. Каждая цель предусматривает свою трактовку этой категории и механизм ее расчета.

В настоящее время определение и расчет прибыли в отечественной системе бухгалтерского учета подчиняются соответствующей бухгалтерской процедуре, регулируемой нормативными документами. Так, согласно пункту 79 Положения по ведению бухгалтерского учета и бухгалтерской отчетности в РФ, «прибыль 
(убыток) представляет собой конечный финансовый результат (прибыль или убыток), выявленный за отчетный период на основании бухгалтерского учета всех хозяйственных операций организации и оценки статей бухгалтерского баланса по правилам, принятым нормативными правовыми актами по бухгалтерскому учету». Порядок расчета финансового результата деятельности организации отражен в ПБУ 4/99 «Бухгалтерская отчетность организации».

Чем объясняется множественность трактовок прибыли и что лежит в основе методологии определения финансового результата в современном законодательстве предстоит узнать в этой работе.

Поиском правильной интерпретации понятия «прибыль» занимались выдающиеся экономисты-теоретики, которые связывали ее с капиталом и богатством. Так, у А. Смита (1723-1790) прибыль есть приращение богатства. И. Фишер (1867-1947) называл прибылью поток генерируемых капиталом выгод за данный промежуток времени [1]. Подобный подход был дан также Дж. М. Кейнсом (1883-1946), который понимал под прибылью выгоду, приносящую капиталом сверх его первоначальной стоимости.

Трактовка прибыли, связанная с капиталом, является отражением статической балансовой концепции, согласно которой прибыль или убыток представляет собой приращение или потери имущества организации. Поскольку основной задачей статической теории являлись оценка финансового состояния компании и определение в связи с этим реальной стоимости имущества, прибыль рассчитывалась следующим образом: проводилась инвентаризация имущества компании через заданные промежутки времени (как правило, год), производилась оценка этих активов по отдельности исходя из их фиктивной продажи. После чего определялась величина чистых активов (активы за минусом кредиторской задолженности), которая сопоставлялась с величиной чистых активов за прошлый период [2].

Таким образом, прибыль, согласно данной трактовке, — это прирост капитала собственников организации за отчетный период без учета операций по преднамеренному его изменению, который означает увеличение ее чистых активов. К преднамеренным изменениям капитала, как правило, относят наращивание капитала за счет дополнительной эмиссии акций или уменьшение части капитала на сумму выплаченных дивидендов [9].

Очевидно, что статическая трактовка требует «правильной» справедливой стоимости имущества, однако это возможно только в результате постоянной переоценки активов, к тому же процесс регулярных переоценок весьма трудоемок и дорог и неизбежно носит субъективный характер. Отсюда и величина прибыли носит условный характер. Еще В. Патон (1889-1991) заметил, что статическая прибыль подвержена влиянию конъюнктуры, поскольку «возникает внезапно, "порывом ветра", благодаря особому случаю, свершающемуся в основном в сфере продаж» [10].

Статическое понимание прибыли как результата работы инвестиций нашло свое отражение в концепции сохранения (поддержания) капитала, задекларированной на сегодняшний день в МСФО.

Теоретические конструкции МСФО базируются на идеях Дж. Хикса, сторонника концепции поддержания капитала, согласно которым полученная прибыль есть величина, превышающая сумму, необходимую для восстановления вложен- 
ных ресурсов в оценке на текущую дату. Это означает, что при расчете следует непременно учитывать фактор обесценения денежных средств, влияние инфляции и пр. Согласно МСФО капитал рассматривается не столько как результат прошлых событий, а сколько итог текущей оценки ресурсов с целью принятия инвестиционных решений на будущее, поэтому оправдано применение оценки ресурсов по дисконтированной стоимости будущих денежных потоков [2].

В рамках статического баланса существует еще один подход, который берет начало в трудах И. Фишера. Он является следствием влияния оценки ценных бумаг, когда акция стоит не столько, сколько за нее заплатили, а столько, сколько она в состоянии приносить дивидендов. Соответственно, прибыль здесь рассматривается как увеличение капитала вследствие изменения его доходности и она не зависит от стоимости имущества. Однако автор этого экономического подхода не учел один важный момент: полученная в прошлом периоде прибыль не имеет никакой ценности для оценки будущего капитала, она вводит в заблуждение администрацию [7].

Таким образом, есть текущая бухгалтерская оценка актива, связанная с полученным результатом, а также есть экономическая оценка актива, разницу между ними назвали гудвиллом. Если гудвилл положительный, то это означает, что предприятие заработало прибыль на капитал больше, чем если бы средства хранились в банке, при отрицательном гудвилле - полученная прибыль меньше, чем при альтернативном хранении средств в банке [5].

В условиях динамического баланса основной целью учета является определение подлинного финансового результата компании, но не за весь период жизнедеятельности, а за искусственно выделяемый отчетный период. Для этого на основе баланса осуществляются наблюдение, контроль и управление кругооборотом капитала (Д - T - Д) с целью получения промежуточных итогов - прибыли или убытка. Центральными категориями динамического учета становятся доходы и расходы.

Тем самым динамическая концепция привела к тому, что прибыль организации стала индикатором эффективности ее текущей деятельности, и поскольку динамическая прибыль трактуется как результат продажи товаров, работ и услуг, ее часто называют бухгалтерской.

Согласно динамической трактовке прибыль или убыток от текущей деятельности получают путем сопоставления доходов и расходов: соответственно, доходы - это поток средств (материальных и финансовых), входящих в предприятие, а расходы - поток средств, выходящих из предприятия.

Пропагандисты динамического баланса всегда подчеркивали, что главная задача счетоведения заключается в правильном распределении доходов и расходов по отчетным периодам [3]. Для того чтобы реализовать принцип идентификации, важнейший принцип динамического баланса, следует факты хозяйственной жизни соотнести с отчетными периодами. Расходы и доходы необходимо формировать исходя из возникновения обязательства независимо от поступления или выбытия денежных средств, т. е. действует принцип начислений. Этот принцип позволяет соотнести доходы и расходы таким образом, чтобы обеспечить равномерное распределение финансовых результатов в рамках каждого отчетного пе- 
риода, кроме того, появляется возможность определить моменты возникновения обязательств и требований по договорам [8].

С развитием счетоводства и счетоведения бухгалтерами стали применяться различные приемы и способы, позволяющие более достоверно исчислить финансовые результаты хозяйствующих субъектов. К инструментам регулирования относятся капитализация и резервирование.

В рамках динамической концепции особое внимание уделяется различию понятий «расходы» и «затраты». Разница между ними связана с процедурой капитализации, позволяющей интерпретировать расходы как оплаченные или подлежащие оплате активы, а затраты как результат уже списанных активов. Капитализация предполагает отражение в составе активов несписанных на затраты расходов, а декапитализация означает, что в этом отчетном периоде расходы уже списаны.

Капитализация расходов вызвана тем, что некоторые расходы обеспечивают получение доходов в последующих отчетных периодах, т. е. их не показывают в составе расходов текущего отчетного периода, а отражают в составе активов, например:

1) в стоимости ценностей, когда произведенные расходы, например, по приобретению товаров, не считаются таковыми, а рассматриваются как увеличение актива. Расходом затраты на покупку этого актива станут исключительно после его реализации, т. е. наблюдается отсрочка в идентификации расходов;

2) в составе дебиторской задолженности, когда за услуги или за аренду было уплачено вперед, и принцип идентификации предполагает разделение этого платежа по отчетным периодам, к которым относятся соответствующие суммы;

3) в составе расходов будущих периодов, когда расходы произведены в данном отчетном периоде и лишены объекта капитализации, за исключением времени. Например, есть перспективные расходы по разработке новой модели продукции, их следует, согласно принципу идентификации, капитализировать и списывать в течение $\mathrm{t}$ лет.

В силу того, что капитализация в расходы будущих периодов не имеет объекта, в отличие от капитализации в ценности и дебиторскую задолженность, возникает соблазн вуалировать отчетность: сокращение дебиторской задолженности, завышение прибыли с целью выплаты высоких дивидендов, искажение показателей бухгалтерской отчетности [6].

Резервирование предполагает регистрацию возможных, предполагаемых или вероятных фактов хозяйственной жизни, т. е. позволяет минимизировать риск от предстоящих расходов, сделав потенциальные расходы неминуемыми сегодня в данном отчетном периоде. Это возможность формировать расходы сейчас, когда их реально еще не было. Примерами создаваемых резервов могут быть резервы нормируемых потерь, резерв на сомнительную дебиторскую задолженность, резерв на расходы по выплате отпускных, на ремонт и т. д. Соответственно резервирование также является следствием принципа идентификации, когда расходы показываются в том отчетном периоде, в котором благодаря им были получены доходы, и доходы отражаются в том периоде, когда были совершены расходы, связанные с ними. 
Однако существуют определенные ограничения, связанные с исчислением прибыли в динамическом балансе. В частности, крайне сложно распределить затраты по периодам согласно принципу соответствия доходов расходам [4]. Как правильно определить, в каком периоде повлекут за собой получение соответствующих доходов такие расходы, как реклама, аудиторские услуги, юридические услуги, расходы на НИОКР.

И здесь опять идет речь о субъективном подходе при капитализации и декапитализации расходов. Можно привести пример общих косвенных расходов, которые можно включать в себестоимость, и тем самым признать их в составе полноценных активов, а можно и сразу декапитализировать, включив их в состав расходов отчетного периода. Условность определения себестоимости продолжается и тогда, когда применяются разные коэффициенты распределения косвенных затрат, согласно методу, выбранному в учетной политике. Все эти приемы в конечном итоге отражаются на величине финансового результата, поскольку именно бухгалтер формирует себестоимость.

Сложность вызывает неоднозначность такой категории, как амортизация, вытекающей из принципа разграничения отчетных периодов и концепции непрерывной деятельности предприятия, а также необходимость определения срока полезного использования активов. На сегодняшний день для бухгалтерского учета установлено четыре варианта начисления амортизации, а для налогового учета - два, и это еще не предел [5]. Выбор того или иного варианта формирует свою величину декапитализированных расходов. Из этого следует, что субъективность в оценке амортизации, начислении резервов, распределении косвенных затрат, способах расчета израсходованных и проданных материалов, товаров и готовой продукции и т. д. неизбежно влияет на величину прибыли, тогда возникает вопрос о возможности определения истинной прибыли.

В итоге можно констатировать, что в основе методологии определения финансового результата в отечественном законодательстве доминирует динамическая трактовка прибыли, в формировании которой важны системность отнесения фактов хозяйственной жизни к доходам и расходам, требование выделения отчетных периодов и применение оценочных и расчетных показателей затрат. Кроме того, действующее законодательство предполагает вариативность при расчете финансового результата от текущей деятельности, и, соответственно, прибыль рассчитывается в результате использования бухгалтером расчетных величин [9].

Таким образом, следует указать на крайнюю неоднозначность категории «прибыль», статическая трактовка которой различается от динамической тем, что последняя ориентируется на уже прошедшее время, в то время как статическая - на время будущее. При этом важно учесть, что бухгалтерская прибыль формируется как сальдо результатных счетов и зависит от выбранной методологии, а экономическая получается в результате дисконтирования вложенных активов и подвержена влиянию конъюнктуры.

\section{Литература}

1. Ковалев Вит. В. Прибыль: трактовка и виды // Вестник Санкт-Петербургского университета. Сер.8. Финансовый менеджмент. 2003. Вып. 4. (№32). С. 86-105. 
2. Нидлз Б., Андерсон Х, Колдуэлл Д. Принципы бухгалтерского учета: пер. с англ. / под ред. Я. В. Соколова. 2-е изд. М.: Финансы и статистика, 1994. 496 с.

3. Обербринкманн Ф. Современное понимание бухгалтерского баланса: пер. с нем. / под ред. проф. Я. В. Соколова. М.: Финансы и статистика, 2003. 416 с.

4. Пятов М. Л. Эволюция методологии бухгалтерского учета в рамках балансовой модели фирмы // Вестник Санкт-Петербургского университета. Сер. 5. Бухгалтерский учет, аудит. 2014. Вып. 4. С. 56-75.

5. Ришар Ж. Бухгалтерский учет: теория и практика: пер с фр. / под ред. Я. В. Соколова. М.: Финансы и статистика, 2000. 160 с.

6. Романова С. А. Анализ методологии бухгалтерского баланса: автореф. дис. ... канд. экон. наук: 08.00.12 Бухгалтерский учет, статистика. СПб., 2005. 25 с.

7. Романова С. А. О природе бухгалтерского баланса. Послесловие // Обербринкманн Ф. Современное понимание бухгалтерского баланса / пер. с нем. С. А. Романовой. М.: Финансы и статистика, 2003. С. 334-363.

8. Соколов Я. В. Бухгалтерский учет как сумма фактов хозяйственной жизни: учеб. пособие. М.: Магистр; ИНФРА-М, 2010. 224 с.

9. Соколов Я. В., Пятов М. Л. Финансовый результат как цель бухгалтерского учета // Бухгалтерский учет. 2007. № 21. С. 56-59.

10. Соколов Я. В., Пятов М. Л. Бухгалтерский учет для руководителя: учеб.-практ. пособие. 3-е изд., перераб. и доп. М.: Проспект, 2005. 232 с.

11. Соколов Я. В. Основы теории бухгалтерского учета. М.: Финансы и статистика, 2000. $496 \mathrm{c}$.

12. Соколов Я. В. Бухгалтерский учет: от истоков до наших дней: учеб. пособие для вузов. М.: Аудит, ЮНИТИ, 1996. 638 с.

13. Ткачук Н. В. Синтетическая концепция бухгалтерской (финансовой отчетности): дис. ...д-ра экон. наук: 08.00.12 Бухгалтерский учет, статистика. СПб., 2019. 320 с.

14. Хендриксен Э.С., Ван Бреда М.Ф. Теория бухгалтерского учета: пер. с англ. / под ред. проф. Я. В. Соколова. М.: Финансы и статистика, 2000. 576 с.

\section{TREATMENT OF PROFIT FROM THE PERSPECTIVE OF BALANCE SHEET ACCOUNTING CONCEPTS}

\section{Tsyremzhit N. Yandanova}

Cand. Sci. (Econ.), A/Prof.,

Dorzhi Banzarov Buryat State University

24a Smolina St., Ulan-Ude 670000, Russia

E-mail: bzn77@mail.ru

The article considers the treatment of profit from the perspective of basic balance sheet accounting concepts. We have discussed the features and limitations of the methodology for financial results formation within the static conception, which formed the basis for IFRS theoretical constructions, as well as the influence of the dynamic accounting conception on the current procedure for establishment of the financial results of economic operators. The article analyzes the main differences between the concepts of expenses and costs, the basic accounting techniques that regulate the financial results formation in terms of the principles of identification, accruals, and matching of income and expenditure. It is emphasized the conventionality and ambiguity of the profit margin due to the subjective assessment of depreciation, accrual of provision for unused vacations, classification of indirect expenditures, procedure for calculation of consumed and sold materials, goods and final products. Keywords: profit; static conception; dynamic conception; income; expenditure. 